\title{
A COMPETÊNCIA PARA LEGISLAR SOBRE A RADIODIFUSÃO COMUNITÁRIA
}

\section{Aécio Flávio Palmeira Fernandes}

Aluno graduado pela FA7 em 2008.1, cuja monografia resultou no presente artigo, sob orientação do Prof. Ms. Felipe dos Reis Barroso. aeciofernandes@zipmail.com.br

Sumário: Introdução. 1) Uma questão histórica. 2) Divisão de competências pela Constituição Federal de 1988. 3) Competência da União. 4) Competência dos Municípios. 5) Regulamentação das Telecomunicações no Brasil. Considerações finais.

Resumo: O presente trabalho busca uma análise acerca dos debates travados no mundo jurídico entre os que defendem a competência legislativa da União Federal e os que defendem a competência legislativa dos Municípios para regular a atividade de radiodifusão comunitária. $\mathrm{O}$ estudo se baseia nas disposições constitucionais acerca da distribuição de competências, no princípio federativo e nas disposições legais pertinentes ao tema, observando com um enfoque analítico a situação da Lei $\mathrm{n}^{\circ}$. 8.612, de 20 de fevereiro de 1998, que regulamenta, a nível nacional, o serviço de radiodifusão comunitária. Além disso, a análise realizada nos leva a concluir que a competência legislativa para o assunto é própria dos municípios, cabendo à União o papel de instituir normas reguladoras de diretrizes gerais que não permitam a permanência de condições e/ou fatos que obstem o funcionamento de outros serviços de radiodifusão, telecomunicação ou que comprometam a segurança aeroespacial no território brasileiro.

Palavras-chave: Rádio Comunitária. Direitos fundamentais. Federalismo. Competência legislativa. Telecomunicações.

\section{INTRODUÇÃO}

Denominação criada pela Lei $n^{\circ}$. 8.612/98, as rádios comunitárias ou RadComs desempenham importante papel na comunidade, atuando de forma concreta nos eventos desta e realizando ações em prol do desenvolvimento social da população local. Pré-sintonizadas em uma freqüência definida pela Agência Nacional de Telecomunicações ANATEL, as rádios comunitárias devem atender aos requisitos legais e às especificações técnicas definidas pelo Poder Público. 
Não devemos confundir as rádios comunitárias com as rádios piratas. As primeiras utilizam-se para seu funcionamento de equipamentos homologados pela União, operam abertamente com estatutos registrados em cartório, endereço registrado e fixo, possuem potência baixa e alcance limitado. Além do mais, os equipamentos de transmissão serão pré-sintonizados na freqüência de operação designada para o serviço.

As rádios piratas, por sua vez, têm essa denominação proveniente da ilegalidade de sua transmissão, já que não utilizam equipamentos pré-sintonizados, ajustados em freqüência adequada e não possuem transmissores homologados pela ANATEL, o que causa sérios problemas em outros serviços de telecomunicações e até mesmo nas navegações aéreas As rádios clandestinas funcionam à revelia da lei e o seu funcionamento é crime definido pelo art. 70 da Lei $\mathrm{n}^{\circ}$. 4.117/62, o Código Brasileiro de Telecomunicações, pois não se enquadram, pelo critério da especialidade, no tipo legal de rádio comunitária.

Para tratar do assunto telecomunicações, temos três espécies legais que dispõem sobre o tema, não esquecendo que a expressão abrange os serviços de telecomunicação, de radiodifusão e de transmissão de dados, e de sons e imagens.

A primeira das leis e também a mais antiga é a Lei $n^{\circ} .4 .117 / 62$, conhecida como Código Brasileiro de Telecomunicação CBT. Apesar de ser uma lei remanescente do tempo da ditadura (que procurava calar os opositores do regime militar, que perduraria por quase três décadas), ela até hoje é utilizada para regulamentação da radiodifusão de grande potência e das rádios comerciais.

A segunda lei é, na ordem cronológica, a Lei $n^{\circ}$ 9.472/97 que instituiu a nova Lei Geral das Telecomunicações LGT, e revogou o antigo Código Brasileiro de Telecomunicação, exceto quanto à matéria de radiodifusão comercial e de grande potência, que continua de competência do antigo código, como acima foi dito.

E, por fim, a Lei $n^{0} 9.612 / 98$, que é a legislação federal específica para disciplinar a radiodifusão comunitária, definida como a transmissão em freqüência modulada (FM), com potência e sistema irradiante limitados, respectivamente, em $25 \mathrm{~W}$ e 30 metros, e alcance restrito a um bairro ou vila, com finalidades sócioculturais e educativas, objetivando a conscientização social da população local.

Diante dessa última lei, iniciar-se-á o trabalho abordando a questão da competência definida pela Constituição Federal de 1988, analisando-se, com base no princípio federativo que norteia o Estado brasileiro, a verdadeira intenção do legislador constituinte originário e o embate acerca da constitucionalidade de alguns artigos da Lei das RadComs.

\section{UMA QUESTÃO HISTÓRICA}

Antes de adentrar na legislação de maneira específica, podemos perceber, até mesmo por aspectos históricos, um aparente entrave na competência legislativa 
para o assunto. Aparente porque a Constituição Federal de 1988 disciplina a competência de cada ente federativo, de modo que não sejam conflitantes, mas por conta de uma prática histórica, o poder executivo, materializado horizontalmente na União, acaba por editar normas de competência municipal.

Seguindo a linha de raciocínio estabelecida por Silveira (2001), apesar de haver uma Constituição vigente no Império, o imperador concentrava em suas mãos os poderes executivo e moderador, onde este último seria a chave de toda organização política do Império. Competia ao chefe desses poderes a distribuição de cargos públicos aos seus amigos ou pessoas por eles indicadas, podendo nomear e demitir livremente ministros de Estado, nomear senadores, convocar trabalhos da Assembléia Geral, dissolver a Câmara dos Deputados e suspender os magistrados (Constituição Federal de 1824, arts. 101 e 102).

A Constituição de 1981 procurou dividir o poder político então concentrado nas mãos do Imperador. A república criou vários mecanismos para obter esse fim, dentre eles a independência dos três poderes, o federalismo e a adoção da doutrina de freios e contrapesos.

O federalismo, no qual se assenta a democracia brasileira e ao qual vamos nos ater momentaneamente, é estruturado de forma que os Estados possuam autonomia interna e independência, obedecendo, porém, a uma Constituição única.

Inspirado no federalismo norte-americano, no Brasil o processo de federalização ocorreu de forma centrífuga, ou seja, parte-se do centro unificado pela concentração dos poderes nas mãos do imperador e repartem-se competências entre a União, os Estados-membros e os Municípios. Lembre-se, inclusive, que a figura dos Municípios foram inovações brasileiras ao princípio federalista norte-americano.

Nosso federalismo, como instrumento de descentralização do poder político, ainda não vingou completamente. Isso porque na fase colonial a descentralização do poder ocorreu de forma desorganizada, dando origem a oligarquias que centralizavam o poder local e porque no Império a centralização do poder se deu de forma asfixiante nas mãos do imperador, perdurando até hoje o desrespeito à competência dos entes políticos municipais.

A repartição das competências material e legislativa devem se dar em conformidade com o princípio federalista, cabendo a cada ente federativo uma matéria de sua competência exclusiva, material comum e legislativa concorrente.

[.... à União caberão aquelas matérias e questões de predominante interesse geral, nacional, ao passo que aos Estados tocarão as matérias e assuntos de predominante interesse regional, e aos Municípios concernem os assuntos de interesse local. (Silva, 1989, p. 415). 
O que ocorre no caso brasileiro é que o poder continua centralizado, desta vez nas mãos do Congresso Nacional e, principalmente do Presidente da República, que detém o poder de editar Emendas Constitucionais sem qualquer participação popular ou das Assembléias Legislativas dos Estados-membros. Não é esse o propósito do sistema federalista e, por isso, afirmamos a nossa opinião de que ele se encontra inacabado.

O federalismo original, como princípio estruturante, prevê a União e os Estados-membros como entes políticos e, a inclusão dos Municípios como tal é inovação brasileira, fruto, talvez, do prestígio conquistado pelo coronelismo das oligarquias locais que queriam sua parcela de poder político no âmbito local.

\section{Divisão de competênCias pela Constituição Federal DE 1988}

Diante dessas peculiaridades e da baixa área de abrangência de uma rádio comunitária, uma leitura do art. 30, I da Constituição Federal de 1988 nos dá a interpretação clara e expressa de que o constituinte reservou ao Município os assuntos de interesse local. $\mathrm{O}$ dispositivo expressamente assegura que aos Municípios é reservada competência privativa para "legislar sobre assuntos de interesse local" e, até aqui, tudo bem. O problema surge quando uma norma federal, como é o caso da Lei $n^{\circ}$. 9.612/98, invade a esfera de competência do Município, editando normas específicas de interesse local e objetivando aplicá-las a todo território nacional.

Interesse local não diz respeito apenas ao interesse exclusivo do Município, mas que afete predominantemente a população local, visando à definição da competência de acordo com o caso concreto. Assim, o interesse local há de ser predominante e, a partir das lições de Meirelles (1997), a ação do Município será legitimada pela aferição do interesse local, que deverá ser de interesse predominantemente local em relação aos interesses das outras entidades federativas.

Aos Estados-membros, a legislação que lhe compete será aquela de interesse regional, quando envolver matérias que não sejam de competência municipal e que não sejam de abrangência nacional. $\mathrm{O}$ art. $25, \S 1^{\circ} \mathrm{da}$ Carta Magna estabelece que a eles são reservadas "as competências que não lhes sejam vedadas por esta Constituição". Assim, também aos Estados-membros é vedada a intervenção nos Municípios, exceto nas situações excepcionais contidas no texto constitucional (CF, art. 35).

Já a União disporá de poderes legislativos limitados, cabendo legislar somente quando em assunto de interesse nacional que envolva mais de um Estado-membro. Sua competência é constituída de maneira subsidiária, geral, ou seja, aquilo que não for de competência do Município, nem de caráter regional e que envolva interesse nacional ou entre dois ou mais Estados será de competência da União. 
A competência legislativa concorrente entre a União e os Estados-membros, descrita no art. 24 da Constituição de 1988, estabelece que, nesse caso, a competência da União limitar-se-á a estabelecer normas gerais.

Aparente conflito resulta da interpretação equivocada do art. 22 da Constituição ao estabelecer competência privativa à União para legislar sobre radiodifusão e telecomunicação. Porém, o art. 22, IV é um princípio e vale mais do que uma norma. Assim, com observância ao princípio federalista e à harmonização das normas constitucionais, não há conflito entre os art. 30, I e o 22, IV, pois naquilo que recair na esfera de competência da União, é de sua privatividade.

Portanto, se tivermos a edição de uma norma federal que dispuser sobre assunto de maneira regional (competência dos Estados-membros) ou local (competência municipal), esta norma deverá ser declarada inconstitucional por não respeitar o princípio federalista adotado pela Constituição.

Em síntese: os municípios deverão ter competência para assuntos de interesse local; os Estados-membros disporão de poderes genéricos ou remanescentes, regionais ou que envolvam dois ou mais municípios; a União terá poderes e competências restritas e enumeradas.

\section{CoMpetênCIA dA UNIÃo}

Como já dito, a competência da União deve ser restringir àqueles assuntos de âmbito nacional ou que envolvam interesses de dois ou mais Estados-membros. A competência deste ente federativo para legislar privativamente sobre radiodifusão e telecomunicações (tomando novamente o art. 22, IV como exemplo) só poderá ser interpretada como sendo uma necessidade imperiosa e premente, de defender direitos ou interesses coletivos de âmbito nacional. Somente dessa forma é que a Constituição admite a intervenção da União para legislar acerca de conflitos envolvendo direitos fundamentais como a livre manifestação do pensamento, a livre expressão da atividade intelectual, artística, científica e de comunicação e o acesso de todos à informação.

Aos que defendem a privatividade da União para legislar sobre radiodifusão (art. 22, IV) e a exclusividade da competência material para "explorar, diretamente ou mediante autorização, concessão ou permissão os serviços de radiodifusão sonora e de sons e imagens" (art. 21, XII, " $a$ "), a leitura das normas constitucionais os leva ao art. 223 da Carta Magna, que expressamente atribui ao Poder Executivo Federal a competência para outorga e renovação das concessões, permissões e autorizações.

Os veículos de comunicação em massa representam um excepcional instrumento para a divulgação de informações, idéias, culturas e é necessariamente um espaço de utilidade pública, constituindo-se, também, área onde o Estado brasileiro exerce sua soberania. 
Aqui, no caso da radiodifusão comunitária, a questão não se mostra absurdamente complexa. Entendemos que se o critério para distribuição de competências utilizado pela Constituição de 1988 é o da predominância do interesse, não se torna estranho pensar que a União tem interesse predominantemente nacional em legislar generalizadamente sobre exploração, autorização, concessão ou permissão dos serviços de radiodifusão sonora e de sons e de imagens que tenham amplo alcance e alta potência. Estranho seria uma norma federal vir legislar especificamente sobre uma rádio comunitária que pretenda se instalar em Santa Cruz de Minas/MG, o menor município do país ${ }^{1}$.

[....] a mera existência de interesses nacionais não dá à União o direito de usurpar ou ignorar a competência municipal, já que a sua competência legislativa nem sempre, necessariamente, exclui a específica do Município, que ela tem o dever de respeitar. (Silveira, 2001, p. 108)

Assim, terá a União competência para fazer o que for preciso para regulamentar o usufruto de direitos fundamentais como os que estão aqui presentes, mas não poderá de forma alguma invadir a esfera de competência estadual ou municipal, desrespeitando o princípio federalista que objetiva a descentralização do poder político que já se encontrava nas mãos do executivo nacional.

A competência da União será exclusiva para editar normas gerais que regulem a exploração do serviço de radiodifusão quando se tratar de interesse nacional ou supra-regional. Nisso, não há o que ser questionado. Porém, quanto à concessão ou autorização do Executivo e do Legislativo federais para o funcionamento de uma rádio comunitária, de alcance restrito e interesse predominantemente local, é se utilizar de uma "bazuca para matar uma barata". E, com base na distribuição das competências com base na predominância do interesse, não há como legitimar a União para editar uma norma que limite a altura da antena em trinta metros como se todo o país fosse plano como uma folha de papel.

Direitos fundamentais, como o direito à liberdade de expressão, de manifestação do pensamento, de informação (aqui compreendendo o direito de informar e de ser informado) são as garantias que os indivíduos possuem contra condutas arbitrárias por parte dos Estados. Dotados dessa proteção, os direitos fundamentais impedem que o Estado imponha sua vontade ilimitada sobre os indivíduos. Bonavides (1997, p. 517), acerca dos direitos fundamentais, leciona:

Os direitos fundamentais são produto peculiar do pensamento liberalburguês do século XVIII, de marcado cunho individualista, surgindo e afirmando-se frente ao Estado, mais especificamente como direitos de

\footnotetext{
${ }^{1}$ Fonte: UFGRS
} 
defesa, demarcando uma zona de não-intervenção estatal e uma esfera de autonomia individual em face de seu poder.

Assim, os direitos fundamentais, protegidos por uma cláusula de imutabilidade, são tidos como cláusulas pétreas. São assim conhecidas porque a sua mutabilidade é vedada ao Estado que encontra uma barreira que protege o indivíduo contra suas ações autoritárias ou abusivas.

Destarte, uma lei que vier a criar limitações para essas liberdades fundamentais deverá ser fundamentada em um relevante interesse público, devendo ser necessariamente imperioso e inadiável, cabendo ao governo o ônus de demonstrar esses requisitos, sob pena de inconstitucionalidade da lei o seu exercício não se encontra vinculado à sua regulamentação por uma lei, seja ela federal, estadual ou municipal. A ausência desta não impede o seu livre exercício, pois são dotadas de auto-executividade e, quando reconhecido expressamente pela Constituição (como é o caso dos direitos em questão), reveste-se ainda de auto-aplicabilidade (Silveira, 2001).

O estabelecimento das competências da União foi realizado através de normas constitucionais. Entre si, estas normas não possuem hierarquia. Porém, quando colocadas diante de direitos individuais fundamentais ou princípios fundamentais, deverão permanecer subordinadas.

O princípio federalista, organizador da divisão do poder político da república, também é um princípio fundamental e, por isso, também é dotado da inatingibilidade de normas tendentes a aboli-lo, revestindo-se de um núcleo pétreo, protegido pela Constituição no seu art. $60, \S 4^{\circ}$.

Assim, adotando a leitura feita por Silveira (2001), a União terá competência privativa para legislar sobre telecomunicações e radiodifusão quando, respeitados os direitos individuais e o princípio federalista, sua competência aflorar, ou seja, quando apresentar a supra-regionalidade ou a nacionalidade que autorize sua atuação.

Competirá à União, havendo interesses comuns ou concorrentes com o Estado ou com o Município, estabelecer normas gerais acerca daquela matéria e essas normas não podem vir a prejudicar o direito daqueles outros entes federativos de legislar especificamente sobre assunto de sua competência. Legislar sobre um assunto tão específico é criar ainda mais entraves burocráticos à concessão do uso de um bem comum do povo.

Assuntos de grande importância nacional ou supra-regional surgem quando passamos à questão da potência máxima dos transmissores, da proteção quanto à interferências ou, ainda, quando tratamos acerca da proteção à aviação e aos aeroportos. Aqui, podemos claramente legitimar a União para estabelecer normas gerais acerca desses temas, pois são de interesse geral e comum a toda federação.

A fixação da potência máxima das rádios comunitárias terá eminente importância nacional e a sua fixação deverá ser realizada com base em estudos 
técnicos que comprovem que o excedente daquela potência estabelecida pode causar efetivo risco de dano a um interesse nacional. Por se tratar de limitação a direito fundamental, o risco real e efetivo deve ser comprovado pela União, não podendo ser arbitrariamente fixado, como ocorreu com os 25 watts ERP fixados pela Lei das RadComs.

\section{COMPETÊNCIA dos MUNICÍPIOS}

Para os que defendem que competência dos municípios para legislar sobre as rádios comunitárias, como é o caso de Silveira (2001), os seguintes aspectos são apontados nos parágrafos que se seguem.

$\mathrm{O}$ primeiro deles diz respeito à competência autônoma e privativa estabelecida pelo art. 30, I da Constituição Federal de 1988 que, ao se utilizar do princípio federativo como fundamental, objetiva descentralizar o poder político das mãos da União. Se a questão do interesse local prevalece sobre qualquer outro, a competência legislativa é do município e nenhuma lei federal ou estadual poderá usurpar questão de sua competência, como, em alguns aspectos, fez a Lei das Rádios Comunitárias ao definir, por exemplo, a altura máxima da antena e da potência, no art. $1^{\circ}, \S 1^{\circ}$.

O segundo aspecto refere-se à limitação da potência máxima em $25 \mathrm{~W}$. Se as ondas de rádio de uma emissora comunitária cruzarem com o de uma rádio mais potente, o efeito de captura fará com que o sinal interferente seja recepcionado e com que a RadCom deixe de operar.

O mais absurdo de tudo isso é que, segundo disposição dos arts. 22 e 23 da lei específica, as RadComs operarão sem direito à proteção contra eventuais interferências causadas por emissoras de quaisquer serviços de telecomunicações e radiodifusão regularmente instaladas e, ainda por cima, estando a RadCom regularmente instalada e nas conformidades da lei, a eventual interferência causada por ela em outros serviços regulares de telecomunicação ou radiodifusão poderá sujeitá-la a interromper sua transmissão. Vejamos o que a lei dispõe:

Art. 22 - As emissoras do Serviço de Radiodifusão Comunitária operarão sem direito a proteção contra eventuais interferências causadas por emissoras de quaisquer Serviços de Telecomunicações e Radiodifusão regularmente instaladas, condições estas que constarão do seu certificado de licença de funcionamento.

Art. 23 - Estando em funcionamento a emissora de Radiodifusão Comunitária, em conformidade com as prescrições desta Lei, e constatando-se interferências indesejáveis nos demais Serviços regulares de Telecomunicações e Radiodifusão, o Poder Concedente determinará a correção da operação e, se a interferência não for eliminada, no prazo estipulado, determinará a interrupção do serviço. 
Quer dizer, além de ter a potência limitada em 25 w ERP, essas rádios, ainda sim, não têm garantidos os seus direitos fundamentais para o seu funcionamento. Sua operação está condicionada a não-interferência por outros serviços. Isso é um flagrante desrespeito aos direitos fundamentais daquelas pessoas que operam e daqueles ouvintes da RadComs.

Em relação ao terceiro aspecto, ninguém melhor que o Município para especificar a área de cobertura de cada emissora, ou seja, qual será a potência necessária para abranger todo aquele território municipal, ou limitar-se a um bairro, vila ou outros setores. O que se critica aqui não é o estabelecimento da potência máxima pela Lei das RadComs, mas a maneira descriteriosa como ela foi estabelecida, sem se comprovar que acima desse limite existe um efetivo risco de relevância nacional.

E o quarto ponto importante é o relevo do Município. Através do estudo e do conhecimento detalhado de suas formas geográficas, somente o Município poderia determinar a altura, posição e direcionamento de suas antenas, a fim de ultrapassar as suas barreiras naturais. A diferença no relevo impede que as ondas se propaguem de maneira uniforme e, dessa forma, somente o município dispõe de mapeamento de seu relevo, através de curvas de nível digitalizadas (Silveira, 2001).

Some-se a estes aspectos a invasão federal à competência legislativa municipal no art. $8^{\circ}$ da Lei das Rádios Comunitárias. A lei estabelece a criação de um Conselho Comunitário para acompanhar a programação da emissora. Está mais que latente a predominância do interesse local ou, em outras e claras palavras, a competência municipal para a questão que, é reconhecida pela própria Lei que viola a Carta Política de 1988.

\section{A RegulamentaÇão das telecomunicaÇõeS no Brasil}

Pela própria Constituição Federal de 1988, os serviços de telecomunicações não são sinônimos de serviços de radiodifusão sonora e de sons e imagens. Isso porque no art. 21, XI, estabelece a competência material da União para "explorar diretamente ou mediante autorização, concessão ou permissão, os serviços de telecomunicações, nos termos da lei,..." e no mesmo artigo, no inciso seguinte, afirma que compete à União "explorar, diretamente ou mediante autorização, concessão ou permissão: a) os serviços de radiodifusão sonora e de sons e imagens".

Para corroborar ainda mais com a distinção acima mencionada, no art. 22, IV, a União tem competência legislativa para legislar privativamente sobre "águas, energia, informática, telecomunicações e radiodifusão".

Antes da EC 8/95, que gerou esse imbróglio, a radiodifusão era uma espécie do gênero telecomunicação. O Código Nacional de Telecomunicação (Lei n ${ }^{\circ}$. 4.117/62) estabelecia que os serviços de radiodifusão compreendiam os serviços 
de radiodifusão sonora e de televisão, depois da redação dada pela Lei n ${ }^{\circ}$. 5.250/67 aos arts. $4^{\circ}$ e $6^{\circ}, d$, do CNT.

O Código Nacional de Telecomunicação CNT, sofreu, ainda em sua fase mais prematura, diversas alterações e, dentre as mais significativas, podemos citar a introdução do polêmico art. 70 da Lei $n^{\circ}$. 4.117/62, introduzido pelo Decretolei $n^{0} .236$, de 28 de fevereiro de 1967. Dessa polêmica que envolve a tipificação penal de algumas RadComs falaremos em tópico específico mais adiante.

Pouco mais tarde, outras modificações importantes foram conferidas pela Convenção Americana sobre os Direitos Humanos (Pacto de São José da Costa Rica), que fora aprovada pelo Congresso Nacional e promulgada pelo presidente Itamar Franco, em 27 de maio de 1992.

Em 1997, surge o novo Código Nacional de Telecomunicação, mais conhecido como Lei Geral das Telecomunicações - LGT (Lei nº 9.472, de 16 de julho de 1997), que define telecomunicação, no seu art. $60, \S 1^{\circ}$, como sendo "a transmissão, emissão ou recepção, por fio, radioeletricidade, meios ópticos ou qualquer outro processo eletromagnético, de símbolos, caracteres, sinais, escritos, imagens e sons ou informações de qualquer natureza".

No seu conteúdo, o novo diploma das telecomunicações estabelece que os serviços de telecomunicação estarão submetidos à exploração mediante os regimes de concessão (regime público de exploração), permissão (intervenção na empresa concessionária e outorga de nova concessão) e autorização (para o regime privado) (Silveira, 2001, p. 132).

$\mathrm{Na}$ LGT, os direitos fundamentais são claramente colocados em plano superior ao Estado repressor, pois o seu art. 128, I, estabelece a liberdade como regra, constituindo-se exceções as proibições, restrições e interferências do Poder Público nos serviços de telecomunicação.

Estabelece, ainda, no seu inciso subseqüente que, salvo por motivo relevante, nenhuma autorização será negada aos que queiram explorar esse serviço. Aqui, a lei, elaborada em texto claro e conciso, explicita aos mais leigos o princípio da livre executoriedade dos direitos fundamentais.

Com a entrada em vigor da Lei Geral de Telecomunicações, o antigo foi revogado, exceto naquilo que se refere à matéria penal e aos preceitos relativos à radiodifusão, já que, em princípio, ela não disciplina a radiodifusão nem trata dos aspectos criminais.

Como conseqüência, a radiodifusão sonora continua sendo mantida de acordo com os termos do Código Nacional de Telecomunicação de 1962, do Decreto-lei $n^{\circ} .236 / 67$, do Decreto $n^{\circ} .52 .026 / 63$ (regulamento geral para execução do CBT) e Decreto $n^{\circ}$. 52.795/63 (regulamento específico dos serviços de radiodifusão).

$\mathrm{O}$ conceito de radiodifusão, dado pela regulamentação do Decreto $\mathrm{n}^{\circ}$. 52.026/63 ao antigo Código Brasileiro de Telecomunicação, "é o serviço de telecomunicações que permite a transmissão de sons (radiodifusão sonora) ou 
a transmissão de sons e imagens (televisão), destinado a ser direta e livremente recebida pelo público".

Atualmente, as telecomunicações estão reguladas pela LGT (Lei $\mathrm{n}^{\circ}$. 9.472/97), enquanto a radiodifusão apenas aquelas de alta potência, incluindo-se aqui as rádios educativas permanece regulamentada pelo CBT (Lei ${ }^{\circ}$. 4.117/62). Lembre-se que, devido ao critério da especialidade, apenas a radiodifusão geral fica nessa situação, já que as rádios comunitárias são reguladas por lei específica (Lei $\left.n^{\circ} .9 .612 / 98\right)$.

\section{(i. CONSIDERAÇÕes FINAIS}

No que diz respeito ao tema deste trabalho, entende-se que a competência para legislar e disciplinar o serviço de radiodifusão comunitária é do Município, pois o âmbito restrito da cobertura da rádio comunitária, os anseios sociais locais e a necessidade de conhecimento de suas peculiaridades o legitimam, conforme o critério de divisão de competências baseado na especificidade.

Por mais que passe despercebido por nós, uma lei federal não vale mais do que uma lei estadual ou municipal. Isso porque elas se situam em dimensões distintas, aonde uma não deve usurpar nem invadir a competência material e legislativa da outra.

Enquanto norma federal a disciplinar a radiodifusão comunitária, a Lei no 9.612/98 deveria abster-se de disciplinar critérios que exigem o conhecimento específico de quem é titular da competência para legislar sobre assuntos de interesse local. Como a lei mesmo que injusta e maculadora dos direitos fundamentais daquelas associações que querem exercê-los também objetiva proteger assuntos de interesse supra-regional e nacional, a União cumpre o seu papel, naquilo que lhe diz respeito.

A política nacional de telecomunicações não pode ser objeto de manobra, de manipuladora da opinião pública como ocorre ainda hoje. Em 2001, um estudo feito pelo Instituto Brasileiro de Geografia e Estatística IBGE, demonstrou que cerca de 70\% (setenta por cento) das emissoras de rádio brasileiras pertencem a políticos ou pessoas a eles ligadas.

$\mathrm{O}$ fato do funcionamento das RadComs depender da autorização emanada do Ministério das Comunicações, lá em Brasília, faz com que direitos fundamentais dependam da morosidade (pra não dizer falta de vontade) do governo em viabilizar as concessões. Isso é um absurdo que jamais deveria ser admitido.

A administração do espectro eletromagnético por onde fluem as ondas de rádio deve ser feita de modo a disciplinar e não a embargar a fruição e o exercício dos direitos fundamentais. Como um bem comum finito, não estamos aqui defendendo a liberação irresponsável do uso do espectro, mas somente 
clamamos pelo empenho e pelo uso do princípio da eficiência, que deveria ser inerente a atuação da Administração Pública. Princípio este que, vitimado pela displicência federal, nada pode fazer diante dos milhares de processos e pedidos de liberação para funcionamento de RadComs engavetados à espera da boa vontade governamental ou de um auxílio corporativo de algum político influente que consiga fazer caminhar a tramitação.

Não contente com o tratamento dispensado às RadComs pelo governo federal, o Município de São Paulo, como muitos outros que estão aderindo à tendência, estão publicando normas legais que disciplinam, agora sim, de maneira correta o serviço de radiodifusão comunitária. Com a faixa de freqüência determinada pelo Ministério das Comunicações, através da ANATEL, estes Municípios disciplinam a instalação e o uso dos equipamentos e das rádios comunitárias sujeitas a sua jurisdição.

Cientes das peculiaridades, do relevo e dos anseios sociais, o Município estabelece a vontade do constituinte originário e faz valer a prerrogativa que lhe foi conferida, utilizando-se, para isso, de meios mais eficazes e céleres na concessão ao uso dessas freqüências para aquele determinado local.

Não estamos, também, argüindo a inconstitucionalidade total da Lei $\mathrm{n}^{\text {o }}$ 9.612/98. Estamos somente defendendo a constitucionalidade daqueles dispositivos que se enquadram na competência da União, procurando argüir a inconstitucionalidade daqueles que não se enquadram no disposto nas normas e nos princípios constitucionais, em especial o do federalismo.

Quanto às normas municipais editadas para disciplinar a radiodifusão comunitária, acreditamos e defendemos a constitucionalidade de tais dispositivos, principalmente quando não usurpam a competência da União. A fixação da altura máxima da antena em 30 metros e a definição dos $25 \mathrm{~W}$ como potência máxima dos transmissores não diz respeito à União, mas ao Município, porque só este entende perfeitamente as peculiaridades locais, estando, desta forma, legitimado pela Carta Política de 1988 a estabelecer as diretrizes desse serviço.

\section{REFERÊNCIAS}

BRASIL. Constituição da República Federativa do Brasil: 1988 texto constitucional de 5 de outubro de 1988 com as alterações adotadas pelas Emendas Constitucionais de $\mathrm{n}^{\mathrm{o}} .1$, de 1992, a 39, de 2002, e pelas Emendas Constitucionais de Revisão de $\mathrm{n}^{\circ} .1$ a 6, de 1994. 20ª . ed. Brasília: Câmara dos Deputados, Coordenação de Publicações, 2003.

. Lei Federal $n^{\circ}$. 4.117, de 27 de agosto de 1962. Institui o Código Brasileiro de Telecomunicações. Brasília, 1962. Disponível em: <http://www. planalto.gov.br/ccivil/leis/L4117.htm>. Acesso em: 04 abr. 2007. 
. Lei Federal $n^{\circ}$. 9.472, de 16 de julho de 1997. Dispõe sobre a organização dos serviços de telecomunicações, a criação e o funcionamento de um órgão regulador e outros aspectos institucionais, nos termos da Emenda Constitucional no . 8, de 1995. Brasília, 1997. Disponível em: <http://www.planalto. gov.br/ccivil/leis/L9472.htm>. Acesso em: 16 abr. 2007.

. Lei Federal no. 9.612, de 19 de fevereiro de 1998. Institui o Serviço de Radiodifusão Comunitária e dá outras providências. Brasília, 1998. Disponível em: $<$ http://www.planalto.gov.br/ccivil/Leis/L9612.htm>. Acesso em: 03 abr. 2007.

BONAVIDES, Paulo. Curso de Direito Constitucional. 10a ed. São Paulo: Malheiros, 1997.

IBOPE (Brasil). Mídia e mercado O investimento do capital estrangeiro no Brasil. São Paulo. Publicado em 03 de out. de 2001. Disponível em: < http://www.ibope. com.br/calandraWeb/servlet/CalandraRedirect?temp $=6 \& p r o j=P o r t a l I B O P E \& p u$ $\mathrm{b}=\mathrm{T} \& \mathrm{db}=$ caldb \&comp $=$ pesquisa_leitura\&nivel $=$ null $\&$ docid $=57019 \mathrm{~F} 4 \mathrm{DCC} 0976$ 2783256ECA00657A5D >. Acesso em: 16 jan. 2008.

MEIRELLES, Hely Lopes. Direito Administrativo brasileiro. 22ª ed. São Paulo: Malheiros, 1997.

NOBRE, Freitas. Imprensa e liberdade: os princípios constitucionais e a nova legislação. São Paulo: Summus, 1988.

SILVA, José Afonso da. Curso de direito constitucional positivo. $5^{\text {a }}$ ed. São Paulo: Revista dos Tribunais, 1989.

Ed. Malheiros, 1996.

. Curso de direito constitucional positivo. $12^{\mathrm{a}}$ ed., São Paulo:

SILVEIRA, Paulo Fernando. Rádios Comunitárias. Belo Horizonte: Del Rey, 2001. 